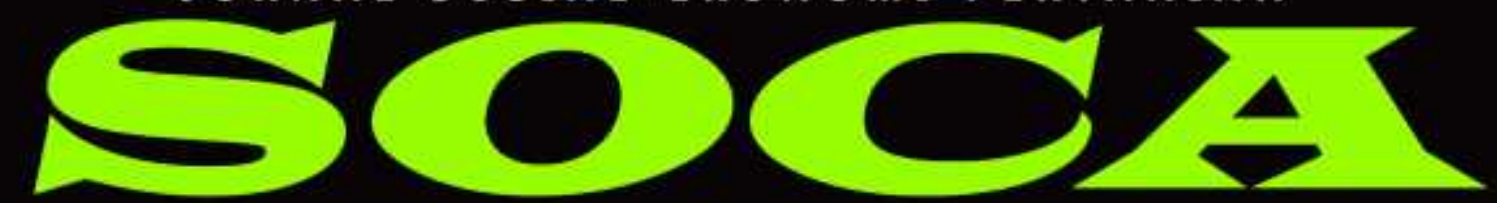

JOURNAL ON SOCIAL ECONOMICS OF AGRICULTURE

Vol.13 No.2 31 Agustus 2019

\title{
ANALISIS FAKTOR-FAKTOR SOSIAL YANG MEMPENGARUHI KEBERHASILAN KELOMPOK TANI HORTIKULTURA DI KELOMPOK WANITA TANI LEGOWO DUSUN KEMRANGGEN KABUPATEN WONOSOBO
}

\author{
Luthfiana Machmudah, Sriroso Satmoko dan Dyah Mardiningsih \\ Program Studi Agribisnis Fakultas Peternakan dan Pertanian \\ Universitas Diponegoro, Kampus Tembalang-Semarang 50275 \\ Email: machmudahluthfiana@gmail.com, tjotjok@yahoo.com dan \\ dyahpeternakan@gmail.com \\ Telepon/HP: 085643007263, 085713691899 dan 087832374455
}

\begin{abstract}
ABSTRAK
Banyak faktor yang berpengaruh terhadap keberhasilan kelompok tani. Faktor tersebut diantaranya motivasi kerja dalam kelompok, penyuluh pertanian, pembinaan oleh pamong desa dan norma kelompok. Keberhasilan kelompok tani dapat dilihat dari keberhasilan kelas belajar, wahana kerjasama, unit produksi dan unit usaha. Tujuan dari penelitian ini adalah untuk menganalisis faktor-faktor sosial (motivasi kerja dalam kelompok, penyuluh pertanian, pembinaan oleh pamong desa dan norma kelompok), menganalisis keberhasilan kelompok dan menganalisis pengaruh faktor-faktor sosial terhadap keberhasilan kelompok. Metode penelitian yang digunakan adalah survei. Sampel penelitian adalah anggota Kelompok Wanita Tani Legowo Wulungsari, Kabupaten Wonosobo. Pengambilan sampel menggunakan metode purposive sampling yaitu sebanyak 30 responden. Analisis yang digunakan yaitu analisis deskriptif dan analisis regresi berganda. Hasil penelitian menunjukkan bahwa tingkat motivasi kerja Kelompok Wanita Tani Legowo tergolong tinggi $(90 \%)$, peran penyuluh pertanian tergolong tinggi $(63,33 \%)$, pembinaan pamong desa sebagian besar tergolong tinggi $(56,67 \%)$ dan norma kelompok tinggi (100\%). Tingkat keberhasilan sebagai unit belajar tergolong sedang $(83,33 \%)$, keberhasilan kelompok sebagai wahana kerjasama tergolong sedang $(83,33 \%)$, keberhasilan kelompok sebagai unit produksi tergolong tinggi $(96,67 \%)$ dan keberhasilan kelompok sebagai unit usaha tergolong sedang $(93,33 \%)$.
\end{abstract}

Kata Kunci: faktor-faktor sosial, hortikultura, keberhasilan kelompok. 


\title{
ANALYSIS OF SOCIAL FACTORS THAT AFFECT THE PROGRESS OF HORTICULTURE FARMING GROUPS IN LEGOWO WOMEN'S FARMER GROUP KEMRANGGEN DISTRICT, WONOSOBO REGENCY
}

\begin{abstract}
Many factors influence progressively by farmer groups. These factors are motivation and spirit to work in a group, agricultural extension agent, coaching by village officials and group norms. The progress of farmer groups could be seen from the learning class values, cooperation's mode, production units and business units. The main purpose of this research is to analyze social factors (motivation and spirit to work in a group, agricultural extension agent, coaching by village officials and group norms), to analyze the progress of groups and to analyze influence of social factors to the progress of groups. The research method was a survey. The research sample was a member of the Legowo Women's Farmer Group Wulungsari, Wonosobo Regency. Sampling used by purposive sampling method, as many as 30 respondents. The analysis used by descriptive analysis and multiple regression analysis. The results of research indicated that the level of work motivation of the Legowo Women's Farmer Group was classified as high (90\%), the role of agricultural extension agent was high (63.33\%), the coaching by village officials was mostly high (56.67\%) and group norms was high (100 $\%)$. The level of high progress learning unit is classified as medium (83.33\%), the group's progress as cooperation's mode classified as medium (83.33\%), the group's progress as a production unit is high (96.67\%) and the progress group as a business unit classified as medium (93.33\%).
\end{abstract}

Keyword: group progress, horticulture, social factors.

\section{PENDAHULUAN}

Kelompok tani dinilai sebagai salah satu solusi untuk mengatasi permasalahan rendahnya posisi tawar petani dan kurangnya daya saing yang dapat menghambat keberhasilan pembangunan pertanian, oleh karenanya masyarakat diharapkan sadar akan pentingnya berkelompok. Kelompok tani merupakan sekelompok petani yang memiliki kepentingan dan tujuan yang sama yang bergabung untuk memajukan usaha agribisnis dan mempermudah pengelolaan dalam proses distribusi, baik itu benih, pestisida, sarana produksi dan lain-lain dalam satu wilayah (Mulyati et al., 2017). Kelompok tani berperan sebagai media musyawarah petani serta sebagai agen pembangunan pertanian diwilayah pedesaan. Sebagai agen pembangunan pertanian kelompok tani memiliki peran/fungsi yakni sebagai kelas belajar, wahana kerjasama, unit produksi dan unit usaha.

Peran kelompok tani sebagai kelas belajar yaitu kelompok sebagai tempat untuk dapat meningkatkan pengetahuan, sikap dan keterampilan dalam berusahatani. Sebagai wahana kerjasama berperan memperkuat kerjasama baik antar sesama anggota kelompok maupun kelompok dengan pihak lain. Sebagai unit produksi kelompok tani berperan untuk menyediakan sarana dan prasarana produksi, hingga pemasaran. Unit usaha berperan dalam meningkatkan kelestarian usaha dan memperoleh keuntungan. Banyak faktor yang mempegaruhi berhasil tidaknya kelompok tani. Faktor-faktor sosial tersebut antara lain motivasi, penyuluh pertanian, pembinaan oleh 
pamong desa dan norma kelompok. Semakin tinggi tingkat pengaruh faktor tersebut maka semakin tinggi pula tingkat keberhasilan kelompok.

Kelompok Wanita Tani Legowo di Dusun Kemranggen Desa Wulungsari Kecamatan Selomerto Kabupaten Wonosobo terbentuk sejak tahun 2005. KWT Legowo bergerak dibidang pemanfaatan pekarangan dengan komoditas hortikultura seperti sayur-sayuran, tanaman hias dan obat-obatan keluarga. KWT Legowo masih bertahan dan terus berupaya mengembangkan kelompoknya dan telah dikenal oleh berbagai daerah di Indonesia.Berdasakan latar belakng tersebut perlu dilakukan penelitian tentang faktor-faktor sosial yang mempengaruhi keberhasilan kelompok tani sebagai unit belajar, kerjasama, produksi dan usaha di KWT Legowo.

Tujuan dari penelitian ini adalah 1) Menganalisis faktor-faktor sosial (motivasi kerja dalam kelompok, penyuluh pertanian, pembinaan oleh pamong desa dan norma kelompok). 2) Menganalisis keberhasilan kelompok. 3) Menganalisis pengaruh faktorfaktor sosial terhadap keberhasilan kelompok.

\section{METODE PENELITIAN}

Penelitian ini dilaksanakan pada bulan November-Desember 2018 di Kelompok Wanita Tani Legowo di Dusun Kemranggen, Desa Wulungsari Kecamatan Selomerto, Kabupaten Wonosobo.

Metode dalam penelitian ini mengunakan metode survei. Metode survei digunakan untuk mendapatkan data secara alamiah (sesuai keadaan sebenarnya) menggunakan kuesioner
(Sugiyono, 2012). Tujuannya untuk memperoleh informasi dari sejumlah responden yang mewakili populasi (Kriyantono, 2009).

Pengambilan sampel menggunakan metode purposive sampling, 30 petani anggota dipilih sebagai sampel. Metode purposive sampling merupakan teknik dengan pertimbangan tertentu dalam pemilihan sampel (Sugiyono, 2016).

Data yang digunakan berupa data primer dan data sekunder. Wawancara dengan menggunakan kuesioner dilakukan untuk memperoleh data primer, sedangkan data yang diperoleh baik dari lapangan, instansi terkait, buku, jurnal, literatur dan referensi lainnya dilakukan untuk memperoleh data sekunder.

Instrumen penelitian yang digunakan adalah kuesioner. Pengukuran instrumen dilakukan dengan skoring 1-5. Jumlah pertanyaan sebanyak 40 pertanyaan. Kategori rendah dengan skor 5-11, sedang 12-18, tinggi 19-25.

Analisis data menggunakan metode analisis statistik deskriptif dan kuantitatif. Metode deskriptif untuk memperoleh data sesuai dengan yang terjadi dan dibandingkan dengan literatur yang ada. Metode kuantitatif dilakukan dengan analisis regresi linier berganda menggunakan program SPSS. Metode regresi linier berganda, yaitu untuk menguji pengaruh kelas belajar, wahana kerjasama, unit produksi serta unit usaha terhadap keberhasilan KWT Legowo menggunakan skala pengukuran dalam persamaan linier. Persamaan umum regresi linier berganda secara menurut Sugiyono (2012) adalah sebagai berikut: 
Keterangan:

$$
\mathrm{Y} 1=\mathrm{a}+\mathrm{b} 1 \mathrm{X} 1+\mathrm{b} 2 \mathrm{X} 2+\mathrm{b} 3 \mathrm{X} 3+\mathrm{b} 4 \mathrm{X} 4+\mathrm{e}
$$

Y : Keberhasilan (kelas belajar, wahana kerjasama, unit produksi, unit usaha) KWT Legowo (skor)

A : Konstanta

X1 : Motivasi kerja dalam kelompok

X2 : Penyuluh Pertanian

X3 : Pembinaan oleh pamong desa

X4 : Norma kelompok

E : Error

b1-b2 : Koefisien regresi, (besar perubahan variabel terkait akibat perubahan tiap unit variabel bebas).

\section{HASIL DAN PEMBAHASAN}

\section{Keadaan Umum Wilayah}

Kecamatan Selomerto adalah kecamatan yang berada di Kabupaten Wonosobo yang secara geografis terletak diantara 7,41670LS dan 109,88590BT (Badan Pusat Statistik, 2018). Penggunaan lahan di Kecamatan Selomerto yaitu 38,82\% sebagai lahan sawah seluas 1.542 ha dan $61,18 \%$ lahan bukan sawah seluas 2.429,490 ha. Desa Wulungsari terletak di Kecamatan Selomerto Kabupaten Wonosobo, secara geografis terletak diantara 7,410LS dan 109,920BT. Luas lahan Desa Wulungsari yaitu $1,08 \mathrm{~km} 2$ atau 107,610 ha.

Tabel 1. Jumlah dan Pesentase Luas lahan dan Penggunaannya 2018.

\begin{tabular}{crrrr}
\hline \multirow{2}{*}{ Penguasaan Lahan } & \multicolumn{2}{c}{$\begin{array}{c}\text { Kecamatan } \\
\text { Selomerto }\end{array}$} & \multicolumn{2}{c}{$\begin{array}{c}\text { Desa } \\
\text { Wulungsari }\end{array}$} \\
\cline { 2 - 5 } & \multicolumn{1}{c}{ Jumlah } & Presentase & Jumlah & Presentase \\
\hline & -- ha--- & $---0^{----}$ & -- ha--- & $----\%----$ \\
Lahan Sawah & & & & \\
a. Irigasi & $1.483,450$ & 37,35 & 68,730 & 63,87 \\
b. Non Irigasi & 58,550 & 1,47 & & - \\
Lahan Bukan Sawah & & & & 23,58 \\
a. Pertanian & $1.910,570$ & 48,11 & 25,370 & 12,55 \\
b. Non Pertanian & 518,920 & 13,07 & 13,510 & 100,00 \\
\hline Jumlah & $3.971,490$ & 100,00 & 107,61 & \\
\hline
\end{tabular}

Sumber: Data Primer Penelitian, 2018.

Jumlah penduduk di Kecamatan Selomerto yaitu 47.038 jiwa yang terdiri dari 23.903 jiwa lakilaki dan 23.135 jiwa perempuan (Badan Pusat Statistik, 2018). Masyarakat Kecamatan Selomerto berpendidikan terakhir SD atau sederajat sebanyak 11.106 dan 950 jiwa diploma/S1/akademi (Data Sekunder Kecamatan, 2018). Mata pencaharian penduduk adalah sebanyak 15.990 jiwa sebagai pekerja lepas dan 1790 jiwa sebagai nelayan
(Data Sekunder Kecamatan, 2018). Jumlah penduduk di Desa Wulungsari sebanyak 1.376 jiwa yang terdiri dari 664 jiwa penduduk lakilaki dan 712 jiwa penduduk perempuan. Pendidikan terakhir masyarakat adalah SD/sederajat sebanyak 518 orang dan 176 orang diploma/S1/akademi. Mayoritas penduduknya bermata pencaharian sebagai pekerja lepas sebanyak 223 orang dan minoritas sebagai pedagang 
sebanyak 33 orang (Data Sekunder

Kelurahan, 2018).

Tabel 2. Jumlah penduduk Desa Wulungsari berdasarkan kelompok Umur dan Jenis Kelamin 2018.

\begin{tabular}{|c|c|c|c|}
\hline \multirow{2}{*}{ Kelompok Umur } & \multicolumn{2}{|c|}{ Jenis Kelamin } & \multirow{2}{*}{ Jumlah } \\
\hline & Laki-laki & Perempuan & \\
\hline --tahun-- & -jiwa- & ---jiwa--- & --jiwa-- \\
\hline $0-4$ & 46 & 68 & 114 \\
\hline $5-9$ & 65 & 70 & 135 \\
\hline $10-14$ & 52 & 64 & 116 \\
\hline $15-19$ & 48 & 41 & 89 \\
\hline $20-24$ & 30 & 20 & 50 \\
\hline $24-29$ & 32 & 37 & 69 \\
\hline $30-34$ & 40 & 46 & 86 \\
\hline $35-39$ & 39 & 55 & 94 \\
\hline $40-44$ & 59 & 53 & 112 \\
\hline $45-49$ & 55 & 50 & 105 \\
\hline $50-54$ & 47 & 48 & 95 \\
\hline $55-59$ & 38 & 42 & 80 \\
\hline $60-64$ & 31 & 26 & 57 \\
\hline $65-69$ & 29 & 31 & 60 \\
\hline $70-74$ & 18 & 15 & 33 \\
\hline $75+$ & 35 & 46 & 81 \\
\hline Jumlah & 664 & 712 & 1.376 \\
\hline
\end{tabular}

Sumber: Data Primer Penelitian, 2018.

Jumlah penduduk di Dusun Kemranggen adalah 401 jiwa dengan penduduk laki-laki 191 jiwa dan prempuan 210 jiwa. Sebagian besar penduduknya berpendidikan terakhir SD yaitu sebanyak 82 orang dan diploma/S1/akademi sebanyak 41 orang. Mata pencaharian penduduk diantaranya sebanyak 42 orang sebagai wiraswasta, 40 orang sebagai

Tabel 3. Jumlah dan Presentase Responden Berdasarkan Umur, Tingkat Pendidikan dan Pekerjaan. petani dan 2 orang sebagai pedagang (Data Sekunder Kelurahan, 2018).

\section{Karakteristik Responden}

Responden yang diambil sebanyak 30 anggota KWT Legowo. Karakteristik responden yang digunakan antara lain umur, pendidikan, dan pekerjaan.

\begin{tabular}{ccc}
\hline Karakteristik Responden & Jumlah & Presentase \\
\hline Umur Responden & - -jiwa--- & $---\%^{----}$ \\
c. $30-40$ & 9 & 30 \\
d. $41-50$ & 13 & 43,3 \\
e. 51-60 & 8 & 26,7 \\
Pendidikan & & \\
c. SD & 7 & 23,3 \\
d. SMP & 7 & 23,3 \\
\hline
\end{tabular}



e. SMA
10
33,3
f. D3
10
g. S1

Pekerjaan
a. IRT
18
60
b. Petani
10
c. Guru
d. Pembibitan
3,3
e. Perangkat Desa
3,3
f. PPL
3,3

Sumber: Data Primer Penelitian, 2018.

Berdasarkan Tabel 3. dapat diketahui usia responden tergolong usia produktif. Kurniasih et al. (2017) menyatakan bahwa usia produktif yaitu antara 15-64 tahun. Pendidikan terakhir responden didominasi pendidikan wajib 9 tahun keatas yaitu SMP hingga S1. Presentase terbanyak adalah SMA yaitu sebanyak 10 orang (33,3\%). Tingkat pendidikan berkaitan dengan pengetahuan dan wawasan. Poluan et al. (2017) menyatakan bahwa tingginya pengetahuan dan wawasan seseorang sesuai dengan tingkat pendidikannya.

Karakteristik responden berdasarkan pekerjaan pada menunjukkan bahwa sebagian memiliki pekerjaan utama sebagai ibu rumah tangga yaitu sebanyak 18 orang (60\%). Ibu rumah tangga memanfaatkan waktunya untuk mengolah/menanam di lahan pekarangan sehingga dapat memperoleh penghasilan tambahan dan menghemat pengeluaran. Hal ini sesuai dengan pendapat Wihartanti (2018) yang menyatakan bahwa fokus ibu rumah tangga lebih kepada ketahanan ekonomi keluarga maupun hanya kegiatan yang bersifat memanfaatkan waktu luang dan sedikit penghasilan.

\section{Motivasi Kerja dalam Kelompok}

Tabel 4. Jumlah dan Presentase Petani Berdasarkan Tingkat Motivasi Kerja Dalam Kelompok

\begin{tabular}{cccc}
\hline \hline \multirow{2}{*}{ Kategori } & \multirow{2}{*}{ Interval Kelas } & Jumlah & Persentase \\
\cline { 3 - 4 } & & -Orang- & $--\%$-- $^{-}$ \\
\hline Rendah & $5-11$ & 0 & 0 \\
Sedang & $12-18$ & 3 & 10 \\
Tinggi & $19-25$ & 27 & 90 \\
\hline Jumlah & & 30 & 100
\end{tabular}

Sumber: Data Primer Penelitian, 2018.

Berdasaran Tabel 4. dapat diketahui bahwa anggota Kelompok Wanita Tani Legowo memiiki motivasi bekerja dalam kelompok yang masuk dalam kategori tinggi, yaitu sebesar 90\%. Motivasi bekerja dalam kelompok dikategorikan tinggi karena KWT Legowo yang melakukan budidaya secara organik mereka mampu memanfaatkan lahan pekarangannya, lingkungan tertata rapi, dapat menghemat pengeluaran serta menambah pemasukan. Sebagaimana pendapat Sukanata dan Yuniati (2016) yang menyatakan bahwa suasana lingkungan yang sehat mendorong timbulnya motivasi petani. Hasil penelitian Hasil penelitian Yusuf (2014) menyatakan bahwa semakin besar motivasi seseorang maka kinerja 
individu dan organisasi akan semakin positif.

\section{Penyuluh Pertanian}

Tabel 5. Jumlah dan Presentase Petani Berdasarkan Tingkat Penyuluh Pertanian

\begin{tabular}{llll}
\hline \multirow{2}{*}{ Kategori } & \multirow{2}{*}{ Interval Kelas } & Jumlah & Persentase \\
\cline { 3 - 4 } & & -Orang- & $--\%--$ \\
\hline Rendah & $5-11$ & 0 & 0 \\
Sedang & 1218 & 11 & 36,67 \\
Tinggi & $19-25$ & 19 & 63,33 \\
\hline Jumlah & & 30 & 100 \\
\hline
\end{tabular}

Sumber: Data Primer Penelitian, 2018.

Tabel 5. menunjukkan bahwa tingkat pengaruh penyuluh pertanian sebesar 63,33\% yang termasuk kategori tinggi. Penyuluh menggunakan metode ceramah, demonstrasi (peragaan) dan diskusi dalam menyampaikan informasi. Hal ini sesuai dengan pendapat Susanto (2008) yang menyatakan bahwa seorang penyuluh (agent of change) harus memiliki kemampuan untuk menempatkan masyarakat sebagai subyek dengan ciri-ciri uniknya, melakukan pendekatan dan

Tabel 6. Jumlah dan Presentase Petani Berdasarkan Tingkat Pembinaan oleh Pamong Desa

\begin{tabular}{llll}
\hline \multirow{2}{*}{ Kategori } & \multirow{2}{*}{ Interval Kelas } & Jumlah & Persentase \\
\cline { 3 - 4 } & & -Orang- & $--\%--$ \\
\hline Rendah & $5-11$ & 1 & 3.33 \\
Sedang & $12-18$ & 12 & 40 \\
Tinggi & $19-25$ & 17 & 56,67 \\
\hline Jumlah & & 30 & 100 \\
\hline
\end{tabular}

Sumber: Data Primer Penelitian, 2018.

Tabel 6. menunjukkan bahwa tingkat pembinaan oleh pamong desa di Kelompk Wanita Tani Legowo sebagian besar tergolong tinggi, yaitu $56,67 \%$. Pamong desa membantu koordinasi antara petani dan penyuluh. Pamong desa menerapkaan budaya gotong royong pada KWT Legowo untuk menjaga keasrian dan kebersihan lingkungan. Oroh (2015) dalam penelitiannya menyatakan bahwa aktivitas pembinaan oleh pamong desa berpengaruh sangat khususnya usahatani. bekerjasama melakukan perubahan serta siap menghadapi penolakan masyarakat terhadap perubahan yang akan dilakukan. Penggunaan metode tersebut sesuai dengan kondisi petani. Hal ini sesuai dengan pendapat Faqih dan Susanti (2015) yang menyatakan bahwa penyuluh harus memilah metode yang efisien dan sesuai dengan keadaan petani agar informasi yang diberikan mudah diterima dan diterapkan.

\section{Pembinaan oleh Pamong Desa}




\section{Norma Kelompok}

Tabel 7. Jumlah dan Presentase Petani Berdasarkan Tingkat Norma Kelompok

\begin{tabular}{cccc}
\hline \multirow{2}{*}{ Kategori } & \multirow{2}{*}{ Interval Kelas } & Jumlah & Persentase \\
\cline { 3 - 4 } & & -Orang- & $--\%--$ \\
\hline Rendah & $5-11$ & 0 & 0 \\
Sedang & $12-18$ & 0 & 0 \\
Tinggi & $19-25$ & 30 & 100 \\
\hline Jumlah & & 30 & 100 \\
\hline
\end{tabular}

Sumber: Data Primer Penelitian, 2018.

Berdasarkan Tabel 7 . dapat diketahui bahwa tingkat pengaruh norma kelompok di KWT Legowo tergolong tinggi yaitu $100 \%$. Menurut responden dengan adanya norma semua anggota memiliki rasa tanggungjawab, saling menghormati sesama anggota sehingga tidak ada yang berbuat seenaknya. Pratisthita (2014) menyatakan bahwa adanya

Tabel 8. Jumlah dan Presentase Petani Berdasarkan Tingkat Keberhasilan sebagai Unit Belajar

\begin{tabular}{cccc}
\hline \multirow{2}{*}{ Kategori } & \multirow{2}{*}{ Interval Kelas } & Jumlah & Persentase \\
\cline { 3 - 4 } & & -Orang- & $--\%$-- $^{-}$ \\
\hline Rendah & $5-11$ & 0 & 0 \\
Sedang & $12-18$ & 25 & 83,33 \\
Tinggi & $19-25$ & 5 & 16,67 \\
\hline Jumlah & & 30 & 100
\end{tabular}

Sumber: Data Primer Penelitian, 2018.

Berdasarkan Tabel 8. dapat diketahui bahwa tingkat keberhasilan sebagai unit belajar termasuk sedang, yaitu sebesar 83,33\%. Adanya penyuluh dan (P4S) Legowo memberikan pengaruh besar terhadap pengetahuan dan sikap petani. Peraturan Menteri Pertanian No.3/Permentan/PP.410/1/2010 yang menyatakan bahwa Pusat Pelatihan Pertanian dan Perdesaan Swadaya (P4S) merupakan lembaga pelatihan petani diharapkan dapat berperan secara aktif melalui pengembangan sumber daya manusia dalam pembangunan pertanian dengan cara pelatihan bagi petani. Setelah mengikuti kelas belajar, petani norma dapat meningkatkan interaksi dan kerjasama serta fungsi dan tugas dalam kelompok. Hasil penelitian tersebut berbeda dengan penelitian Hariadi (2011) yang menyatakan bahwa norma kelompok berpengaruh nyata terhadap keberhasilan kelompok.

\section{Keberhasilan sebagai Unit Belajar}




\section{Keberhasilan sebagai Wahana Kerjasama}

Tabel 9. Jumlah dan Presentase Petani Berdasarkan Tingkat Keberhasilan sebagai Wahana Kerjasama

\begin{tabular}{llll}
\hline \multirow{2}{*}{ Kategori } & \multirow{2}{*}{ Interval Kelas } & Jumlah & Persentase \\
\cline { 3 - 4 } & & -Orang- & $--\%{ }^{--}$ \\
\hline Rendah & $5-11$ & 5 & 1,67 \\
Sedang & $12-18$ & 25 & 83,33 \\
Tinggi & $19-25$ & 0 & 0 \\
\hline Jumlah & & 30 & 100 \\
\hline
\end{tabular}

Sumber: Data Primer Penelitian, 2018.

Berdasarkan Tabel 9. dapat diketahui bahwa tingkat keberhasilan sebagai wahana kerjasama tergolong sedang, yaitu 83,33\%. Keberhasilan kerjasama KWT Legowo sedang, sebab belum mampu bekerjasama dengan pihak luar seperti perusahaan swasta, namun kerjasama didalam kelompok sudah baik. Mutiah et al. (2018) menyatakan bahwa kerjasama yang baik sangat diperlukan untuk

Tabel 10. Jumlah dan Presentase Petani Berdasarkan Tingkat Keberhasilan sebagai Wahana Produksi

\begin{tabular}{cccc}
\hline \multirow{2}{*}{ Kategori } & \multirow{2}{*}{ Interval Kelas } & Jumlah & Persentase \\
\cline { 3 - 4 } & $5-11$ & -Orang- & $--\%$-- $^{-}$ \\
\hline Rendah & $12-18$ & 0 & 0 \\
Sedang & $19-25$ & 1 & 3,33 \\
Tinggi & & 29 & 96,67 \\
\hline Jumlah & & 30 & 100
\end{tabular}

Sumber: Data Primer Penelitian, 2018.

Tabel 10. menunjukkan bahwa tingkat keberhasilan sebagai wahana produksi tinggi, yaitu 96,67\%. Keberhasilan sebagai wahana produksi tinggi, meskipun hasil produksi tanaman yang ditanam tidak terlalu besar namun Kelompok Wanita Tani Legowo selalu berusaha untuk terus berproduksi dan meningkatkan hasil produksi. Thomas (2008) menyatakan bahwa sebagai unit produksi kelompok tani bertugas meningkatkan kemampuan dalam menentukan pola usahatani yang menguntungkan. Hasil penelitian terbentuknya kelompok yang baik. Hasil penelitian Hariadi (2011) menyatakan bahwa keberhasilan kelompok tani sebagai wahana kerjasama dipengaruhi oleh factor interaksi, norma, penyuluh pertanian dan pembinaan oleh pamong desa.

\section{Keberhasilan sebagai Wahana Produksi}




\section{Keberhasilan sebagai Wahana Usaha}

Tabel 11. Jumlah dan Presentase Petani Berdasarkan Tingkat Keberhasilan sebagai Wahana Usaha

\begin{tabular}{cccc}
\hline \multirow{2}{*}{ Kategori } & \multirow{2}{*}{ Interval Kelas } & Jumlah & Persentase \\
\cline { 3 - 4 } & & -Orang- & $--\%{ }^{--}$ \\
\hline Rendah & $5-11$ & 2 & 6,67 \\
Sedang & $12-18$ & 28 & 93,33 \\
Tinggi & $19-25$ & 0 & 0 \\
\hline Jumlah & & 30 & 100 \\
\hline
\end{tabular}

Sumber: Data Primer Penelitian, 2018.

Tabel 14. menunjukkan bahwa tingkat keberhasilan sebagai wahana usaha tergolong sedang yaitu sebesar 93,33\%. Kelompok Wanita Tani Legowo memasarkan hasil pertaniannya kepada pengunjung yang datang atau ke pasar tadisional. Selain itu KWT Legowo memanfaatkan kegiatan diluar seperti expo petanian untuk memasarkan produknya. Hal ini sesuai dengan pendapat Harfina (2017) yang menyatakan bahwa peran kelompok sebagai unit usaha yaitu peran kelompok untuk mencari informasi dan memanfaatkan peluang

$$
\begin{gathered}
\mathrm{Y}=\mathrm{a}+\mathrm{b}_{1} \mathrm{X}_{1}+\mathrm{b}_{2} \mathrm{X}_{2}+\mathrm{b}_{3} \mathrm{X}_{3}+\mathrm{b}_{4} \mathrm{X}_{4}+\mathrm{e} \\
\mathrm{Y}=0,245+1,018 \mathrm{X}_{1}+1,548 \mathrm{X}_{2}+1,218 \mathrm{X}_{3}-0,362 \mathrm{X}_{4}+\mathrm{e}
\end{gathered}
$$

Tabel 12. Hasil Uji Regresi Linier Berganda

\begin{tabular}{lcccccc}
\hline \multirow{2}{*}{ Variabel } & \multicolumn{2}{c}{$\begin{array}{c}\text { Unstandardized } \\
\text { Coefficients }\end{array}$} & $\begin{array}{c}\text { Standardized } \\
\text { Coefficients }\end{array}$ & \multirow{2}{*}{$\mathrm{T}$} & Sig. \\
\cline { 2 - 4 } & $\mathrm{B}$ & $\begin{array}{c}\text { Std. } \\
\text { Error }\end{array}$ & Beta & & \\
\hline Konstanta & 0,245 & 11,606 & & 0,021 & 0,983 \\
\hline $\begin{array}{l}\text { X1 (Motivasi Kerja dalam } \\
\text { Kelompok Tani) }\end{array}$ & 1,018 & 0,353 & 0,374 & 2,886 & 0,008 \\
\hline X2 Penyuluh Pertanian & 1,548 & 0,593 & 0,292 & 2,612 & 0,015 \\
\hline $\begin{array}{l}\text { X3 Pembinaan oleh } \\
\text { Pamong Desa }\end{array}$ & 1,218 & 0,309 & 0,505 & 3,938 & 0,001 \\
\hline X4 Norma Kelompok & $-0,362$ & 0,580 & $-0,082$ & $-0,625$ & 0,538 \\
\hline
\end{tabular}

Sumber: Data Primer Penelitian, 2018.

Konstanta sebesar 0,245, artinya apabila variabel motivasi kerja dalam kelompok tani, penyuluh pertanian, pembinaan oleh pamong desa dan norma kelompok tidak ada demi keberhasilan dan keberlangsungan usaha anggotanya. Hasil penelitian Hariadi (2011) menyatakan bahwa factor-faktor yang mempengaruhi keberhasilan kelompok tani sebagai unit usaha adalah self efficacy, interaksi anggota dan gaya kepemimpinan ketua kelompok.

\section{Analisis Regresi Linier Berganda}

Berdasarkan Tabel 12. diperoleh model persamaan regresi sebagai berikut: atau nilainya adalah 0 , maka keberhasilan kelompok tani nilainya sebesar 0,245. Koefisien regresi variabel motivasi kerja dalam kelompok tani (X1) sebesar 1,018, 
artinya apabila motivasi kerja dalam kelompok tani ditingkatkan 1 satuan, maka keberhasilan kelompok tani mengalami kenaikan sebesar 1,018.

Koefisien regresi variabel penyuluh pertanian (X2) sebesar 1,548 , artinya apabila penyuluh pertanian meingkatkan 1 satuan, maka keberhasilan kelompok akan meningkat sebesar 1,548. Koefisien regresi variabel pembinaan oleh pamong desa (X3) sebesar 1,218, artinya apabila pembinaan oleh pamong desa meningkat 1 satuan, maka keberhasilan kelompok akan meningkat sebesar 1,218. Koefisien regresi variabel norma kelompok (X4) sebesar -0,362, artinya apabila norma kelompok meningkat 1 satuan, maka keberhasilan kelompok mengalami peningkatan, sebesar 0,236 satuan.

Nilai Fhitung sebesar 19,841 dengan nilai Sig sebesar 0,000. Nilai Fhitung yang diperoleh lebih besar dari Ftabel 2,76 dan nilai Sig < 0,05, yang memiki arti bahwa HO ditolak dan Ha diterima. Hal ini berarti variabel motivasi kerja dalam kelompok tani, penyuluh pertanian, pembinaan oleh pamong desa dan norma kelompok secara serempak memiliki pengaruh yang signifikan terhadap keberhasilan.

Nilai thitung dari setiap variabel:

1. Motivasi kerja dalam kelompok tani Nilai thitung yang dihasilkan sebesar 2,886 dan nilai Sig sebesar 0,008. Nilai thitung lebih besar daripada nilai ttabel 2,05954 dan nilai Sig $<0,05$. Dengan demikian Ha diterima dan $\mathrm{HO}$ ditolak. Hal ini berarti variabel motivasi kerja dalam kelompok berpengaruh siginifikan terhadap keberhasilan kelompok.

2. Penyuluh pertanian

Nilai thitung yang dihasilkan sebesar 2,612 dan nilai Sig sebesar 0,015. Nilai thitung lebih besar daripada nilai ttabel yaitu 2,05954 dan nilai sig $<0,05$. Dengan demikian HO ditolak dan $\mathrm{Ha}$ diterima. Hal ini berarti variabel penyuluh pertanian memiliki pengaruh yang siginifikan terhadap keberhasilan kelompok.

3. Pembinaan oleh pamong desa Diperoleh thitung sebesar 3.938 dan nilai Signifikansi sebesar 0,001. Nilai thitung lebih besar daripada nilai ttabel 2,05954 dan nilai Sig $<0,05$. Dengan demikian Ha diterima dan HO ditolak. Hal tersebut memiliki arti bahwa variabel pembinaan oleh pamong desa berpengaruh secara siginifikan terhadap keberhasilan kelompok.

4. Norma kelompok

Diperoleh nilai thitung $-0,625$ dan nilai Sig sebesar 0,538. Nilai thitung lebih kecil daripada nilai ttabel 2,05954 dan nilai Sig >0,05, yang artinya HO diterima sedangkan Ha ditolak. Hal ini berarti variabel norma kelompok tidak memiliki pengaruh yang siginifikan terhadap keberhasilan kelompok.

Uji koefisien determinasi menunjukkan hasil nilai sebesar 0,722 , artinya variabel (X) berupa motivasi kerja dalam kelompok tani, penyuluh pertanian, pembinaan oleh pamong desa dan norma kelompok berpengaruh sebesar $72,2 \%$ terhadap variabel $(\mathrm{Y})$ yang berupa keberhasilan kelompok, sedangkan $27,8 \%$ sisanya merupakan pengaruh dari faktor lain yang tidak diteliti.

\section{KESIMPULAN}

\section{Simpulan}

Secara serempak faktor-faktor sosial (motivasi kerja dalam kelompok, penyuluh pertanin, pembinaan oleh pamong desa dan norma kelompok berpengaruh secara signifikan. Secara parsial noma kelompok tidak 
berpengaruh secara signifikan terhadap keberhasilan kelompok.

\section{Saran}

Sebaiknya tingkat motivasi, penyuluh pertanian dan pembinaan oleh pamong desa yang sudah tergolong tinggi untuk dipertahankan dan ditingkatkan serta norma dalam kelompok untuk diterapkan sehingga dapat meningkatkan keberhasilan kelompok.

\section{DAFTAR PUSTAKA}

Faqih, A. 2016.Peranan Penyuluh Pertanian Lapangan (PPL) dalam kegiatan pemberdayaan kelompok terhadap kinerja kelompok tani. Agrijati Jurnal Ilmiah Ilmu-Ilmu Pertanian. 26(1): 41-60.

Faqih, A., dan Susanti, R. 2016.Efektivitas metode dan teknik penyuluhan pertanian dalam penerpan teknologi budidaya padi sawah (Oryza sativa L.) sistem tanam jajar legowo 4:1. Agrijati Jurnal Ilmiah Ilmu-Ilmu Pertanian. 28(1): 45-67.

Harfina, F. K. 2017. Peranan kelompok dalam mendukung pengembangan kapasitas wanita pedesaan. Students eJournal. 6(1): 1-16.

Hermanto dan Swastika D., K., S. 2011. Penguatan kelompok tani: Langkah awal peningkatan kesejahteraan petani. Jurnal Analisis Kebijakan Pertanian. 9(4): 371- 390.

Kurniasih, D., W. Sudarta dan N. Parining. 2017. Hubungan antara Karakteristik Petani dengan Motivasinya dalam Membudidayakan Tanaman Tebu (Kasus Kelompok Tani
Dewi Ratih 1, Desa Maospati, Kecamatan Maospati, Kabupaten Magetan). J. Agribisnis dan Agrowisata. 6(4): 523-532.

Mulyati, S., D., Rochdiani, dan M. N., Yusuf. 2017. Pengaruh faktor sosial ekonomi petani dan partisipasi petani dalam penerapan teknologi pola tanam padi (Oryza sativa L) jajar legowo 4: 1. Jurnal Ilmiah Mahasiswa Agroinfo Galuh, 3(2): 117-124.

, A., Abdullah, A., dan Nurlaelah, S. 2018. Identifikasi peranan kelompok sebagai wahana kerja sama pada kelompok peternak sapi potong pada peternakan rakyat. Jurnal Agripet. 18(1): 57-62.

Nuryanti.S., dan D. K. S. Swastika. 2011. Peran Kelompok Tani Dalam Penerapan Teknologi Pertanian. Forum Penelitian Agro Ekonomi. 29(2): 115-128.

Oroh, G. S. 2015. Peranan Pemerintah Desa dalam Pemberdayaan Masyarakat di Bidang Pertanian di Desa Tumaratas Kecamatan Langowan Barat Kabupaten Minahasa. Jurnal Politico. 1(5): 1-11.

Perdana, A. S. 2016. Pemberdayaan kelompok tani melalui pasar lelang sebagai solusi mewujudkan kedinamisan kesejahteraan petani. Jurnal Ilmu Pertanian Tropika dan Subtropika, 1(1): 52-63.

Poluan, J., Rantung, V. V., dan Ngangi, C. R. 2017. Dinamika Kelompok Tani Maesaan Waya di Desa Manembo, Kecamatan Langowan Selatan. AgriSosioekonomi: Jurnal Ilmiah 
Sosial

Ekonomi

Pertanian, 13(1): 217-224.

Pratisthita, R. N. 2014. Peran modal sosial dalam menunjang dinamika kelompok peternak sapi perah (Studi Kasus di Kelompok 3 TPK Pulosari Pangalengan). Jurnal ilmu ternak. 14(1): 52-57.

Rifai, A, D. Muwardi., dan J. R. F. N. Rangkuti. 2012. Perilaku Konsumen Sayuran Organik di Kota Pekanbaru. JIP (Jurnal Industri dan Perkotaan). 12(22): 1786-1792.

Setiawan, D. A., Redjeki, E. S., dan Nasution, Z. 2017. Analisis Proses Pembelajaran dalam Konsep Pemberdayaan Kelompok Tani. Jurnal Pendidikan: Teori, Penelitian, dan Pengembangan. 2(8): 10771080.

Sukanata, I. K., dan Yuniati, A. 2016. Hubungan karakteristik dan motivasi petani dengan kinerja kelompok tani. Agrijati Jurnal Ilmiah Ilmu-Ilmu Pertanian, 28(1): 17-34.

Wihartanti, L. V. 2018. Peran Perempuan Kepala Keluarga dalam Menciptakan Kesejahteraan Keluarga. EcoSocio: Jurnal ilmu dan Pendidikan Ekonomi. 2(2): 145152.

Yani, D. E. 2010. Persepsi anggota terhadap peran kelompok tani dalam meningkatkan kemampuan penguasaan teknologi budidaya belimbing. Jurnal Matematika, Sains, Dan Teknologi. 11(2): 133-145.

Yusuf, A. E. 2014. Dampak Motivasi Terhadap Peningkatan Kinerja
Individu. Jurnal

Humaniora. 5(1): 494-500.

Ghozali, I. 2008. Aplikasi Analisis Multivariate dengan Program SPSS. Universitas Diponegoro, Semarang.

, I. 2011. Aplikasi Analisis Multivariate dengan Program IBM SPSS 19. Universitas Diponegoro, Semarang.

Hariadi, S., S. 2011. Dinamika Kelompok: Teori dan Aplikasinya untuk Analisis Keberhasilan Kelompok Tani sebgai Unit Belajar, Kerjasama, Produksi, dan Bisnis. Sekolah Pascasarjana Universitas Gadjah Mada, Yogyakarta.

Igirisa, I. 2010. Faktor-Faktor Yang Menentukan Keberhasilan Dalam Kebijakan Pengembangan Usaha Tani di Kabupaten Gorontalo. Fakultas Ekonomi dan Bisnis. Universitas Negeri Gorontalo.

Kriyantono, R. 2009. Teknik Praktis Riset Komunikasi. Kencana Prenada Media Group, Malang.

Sugiyono.2012. Metode Penelitian Kuantitatif Kualitatif dan R dan D. Alfabeta, Bandung.

Sugiyono. 2014. Metode Penelitian Pendidikan Pendekatan Kuantitatif, Kualitatif Dan R dan D. Alfabeta, Bandung.

Susanto, D. 2008. Peranan Penyuluh Pembangunan dalam Meningkatkan Kualitas SDM. Dalam Pemberdayaan Manusia Pembangunan yang Bermartabat. Pustaka Bangsa Press, Bogor. 
Thomas, S. 2008. Materi Pokok

Dinamika Kelompok.

Universitas Terbuka. Jakarta. 